\title{
Vorinostat Combined with DNA Methyltransferase Inhibitors Epigenetically Controls the Proliferation of Lung Cancer Cells A549
}

\author{
Hussein Sabit $^{1^{*}}$, Mostafa Fathy ${ }^{2}$, Shimaa E. Abdel-Ghany ${ }^{3}$, Osama A. M. Said ${ }^{4}$, Mokhtar M. El-Zawahry ${ }^{5}$ \\ ${ }^{1,2,4,5}$ College of Biotechnology, Misr University for Science and Technology, 6 of October City, Giza, Egypt \\ ${ }^{3,5}$ Center of Research and Development, Misr University for Science and Technology, 6 of October City, Giza, Egypt \\ *Corresponding author, mailto: hussein.sabit@must.edu.eg
}

\begin{abstract}
Cancer is being considered one of the fatal diseases in the global population. Lung cancer is one of the most common malignancies in males and in several countries also in females. In the present study, we aimed at evaluating the role of different chemotherapeutic drugs belonging to three groups [Histone Deacetylase Inhibitors (HDACi), DNA Methyltransferase Inhibitors (DNMTi), and Alkylating Agents)]. Vorinostat, Carboplatin, Cyclophosphamide, Temozolomide, and Procaine were applied to A549 lung cancer cells in final concentrations of $3 \mu M$ and $5 \mu M$. Drugs were incubated with the cells for 96 h. Cell viability was measured using Trypan blue exclusion test, and the obtained results showed a significant decrease in the cells' viability after being treated. Global methylation, as an essential epigenetic mark, was quantified in the control and treated cells. The results showed a variation in the methylation patterns, since different combination yielded different methylation profiles. Vorinostat combined with Carboplatin hypomethylated the cells under study, while Vorinostat combined with Cyclophosphamide resulted in hypermethylation of the cells. We concluded that reactivating the hypermethylated genes in the A549 lung cancer cells by combining more than one drug was significantly better than that induced by only one chemotherapeutic agent. However, these results need more confirmatory experiments.
\end{abstract}

Keywords: Lung. Cancer Epigenetics, Methylation. Vorinostat

\section{Introduction}

Cancer is a term used to describe a disease in which abnormal cells divide in an uncontrolled fashion, and can invade other tissues $[\mathbf{1}, \mathbf{2}]$. Over the last century, lung cancer has become one of the biggest death-causing cancer of men worldwide and in some parts of the world also of women [3]. Two major types of lung cancer are known; small cell lung cancer (SCLC), which represents about $10-15 \%$ of all lung cancers [4], and non-small cell lung cancer (NSCLC) which represents about $85-90 \%$ of all lung cancers $[\mathbf{5}, \mathbf{6}]$.

Although chemotherapy is considered one of the most effective approaches to treat cancer, it might kill, alongside the malignant cell, any normal cell that grows fast, which, in turn, may result in serious damage to patients [7-9]. Most of the chemotherapeutic drugs work by impairing cell division by various mechanisms including damaging DNA and inhibition of the cellular machinery involved in cell division [10].

HDACi's have demonstrated anticancer effects by selectively inducing apoptosis through modulating the expression of pro-apoptotic and anti-apoptotic genes [11]. Vorinostat is one of the inhibitors of HDAC family that shows to be efficacious and well-tolerated drug, thus, it has been considered a novel drug in the treatment of various cancers [12]

Epigenetics as a term was first coined by Conrad Waddington in the early 1940s [13]. He defined epigenetics as "the branch of biology which studies the causal interactions between genes and their products which bring the phenotype into being." [14]. Collectively, epigenetics could be viewed as a major molecular mechanism that control gene expression without changing the underlying DNA sequence. Two major epigenetic mechanisms are known; DNA methylation and histone modification $[\mathbf{1 5}, \mathbf{1 6}]$. It represents the programming of the genome to express an appropriate set of genes in certain cells at specific time points in life. It has a trans generational effect as it could affect the recurrence of such disease in the descendants of cells in the individual $[16,17]$.

Methylation of DNA is considered one of the most important epigenetic mechanisms in mammals [18]. It is a heritable epigenetic mark involving the covalent transfer of a methyl group to the C-5 position of the cytosine ring of DNA by DNA methyltransferases (DNMTs) [19]. This can coordinately regulate the chromatin status via the interaction of DNMTs with other modifications and with components of the machinery mediating those marks [20].

Histone acetylation is generally associated with elevated transcription, while deacetylated histones are often associated with gene repression $[\mathbf{2 1}, \mathbf{2 2}]$. The balance of histone acetylation and deacetylation is critical in the regulation of gene expression. Aberrant expressions of genes that encode HDACs have been linked to tumor development as they dysregulate important cellular functions such as cell proliferation and apoptosis. Thus, HDACs are among the most promising therapeutic targets for cancer treatment $[\mathbf{2 3}$, 24].

The aim of the present investigation is to identify the role of Vorinostat combined with other chemotherapeutic drugs (DNMTi and HDACi) in controlling the proliferation of lung cancer cells A549. 


\section{International Journal of Science and Research (IJSR) \\ ISSN (Online): 2319-7064}

Index Copernicus Value (2015): 78. 96 | Impact Factor (2015): 6. 391

\section{Materials and Methods}

\section{Cell line maintenance}

Lung cancer cells A549 was purchased from the Holding Company for Biological Products and Vaccines (VACSERA, Cairo, Egypt). Cells were maintained in DMEM (Dulbecco's Modified Eagle's Medium, Lonza, USA) supplemented with 10\% Fetal Bovine Serum (Sigma, Germany) and 1\% antibiotic mix (Sigma, Germany). Cells were grown under the normal laboratory conditions; $5 \% \mathrm{CO}_{2}$ and $37^{\circ} \mathrm{C}$.

\begin{abstract}
Application of chemotherapeutic drugs
Chemotherapeutic drugs (Vorinostat, Temozolomide, Carboplatin, Procaine, and Cyclophosphamide) were purchased from Santa Cruz Biotechnology (USA). Each drug was dissolved in the appropriate solvent, and a working stock of $5 \mathrm{mg} / \mathrm{mL}$ was prepared. Two final concentrations of $3 \mu \mathrm{M}$ and $5 \mu \mathrm{M}$ were used in the present study to treat lung cancer cells for $96 \mathrm{~h}$. Vorinostat was applied solely or in combination with other drugs as follows: Vorinostat only, Vorinostat combined with Carboplatin, Vorinostat combined with Cyclophosphamide, Vorinostat combined with Procaine, and Vorinostat combined with Temozolomide.
\end{abstract}

\section{Harvesting the cells}

After $96 \mathrm{~h}$. of incubation, cells were removed from the incubator and the old medium was decanted. Cells were washed twice with warm PBS and trypsinized with $3 \mathrm{~mL}$ of $1 X$ Trypsin EDTA $(0.025 \%)$. Cells were then collected by centrifugation for $10 \mathrm{~min}$. at $10,000 \mathrm{rpm}$.

\section{Cell viability assay}

According to Strober (2001) [25], the number of viable and non-viable cells were counted using Trypan blue exclusion test. Briefly, $50 \mu \mathrm{L}$ of cell suspension was mixed with an equal volume of Trypan blue dye and left for $3 \mathrm{~min}$. at room temperature. The mix was then loaded on a hemocytometer slide to be read using an inverted microscope. Clear cells were considered viable, while blue ones were considered dead.

\section{DNA extraction and DNA fragmentation assay}

Genomic DNA was extracted from treated and untreated cells using Quick-DNATM Miniprep Kit (Zymo Research, USA) following the kit's instructions. After extracting DNA, fragmentation assay was performed to assess the degradation pattern of DNA isolated from control and treated lung cancer cells. Briefly, $5 \mu \mathrm{L}$ of the eluted DNA was loaded on agarose gel $(0.8 \%)$ and subjected to low voltage $(15 \mathrm{~V})$ for $10 \mathrm{~min}$. and then to $120 \mathrm{~V}$ for $30 \mathrm{~min}$.

\section{Methylation quantification}

Global methylation pattern was identified using Methyl Flash DNA methylation kit (Epigentek, USA) following the kit's protocol.

\section{Statistical analysis}

Statistical analysis (ANOVA) for the obtained data was performed using SPSS 22.0.0.0 program that run under Windows [26]. In addition, the differences between means were calculated by using Duncan's Multiple Range test in the same program. Least Significant Difference (LSD) was also used to test the significance between all the treatments and control.

\section{Results and Discussion}

\section{Cell viability}

Trypan blue test was performed to ensure the viability of the cultured cells. This test depends on dye exclusion as the live cells will not allow the dye to enter and, subsequently the live cells will appear clear when being examined under inverted microscope [27]. In this study, the initial cell count was $6 \times 10^{5}$. The results obtained showed a significant decrease in the cell viability after being treated with different concentrations/combinations of the chemotherapeutics compared to control (Figure 1).

Mortality rate ranged from $75 \%$ to $89.6 \%$ with the most effective drug/combination was Vorinostat at the concentration of $3 \mu \mathrm{M}\left(62,500\right.$ viable cells out of $6 \times 10^{5} ; 89$. $6 \%$ mortality rate) and Vorinostat combined with Carboplatin at the concentration of $3 \mu \mathrm{M}(62,500$ viable cells, 89.6\% mortality rate). Ramalingam et al. (2010) [28] demonstrated that Vorinostat, as a HDAC inhibitor, enhances the efficacy of Carboplatin in patients with advanced NSCLC. This was observed also by Owonikoko et al. (2010) [29] who found that Vorinostat lower concentrations $(1 \mu \mathrm{M})$ inhibited the growth of A549 lung cancer cells by $67 \%$. Vorinostat in addition to Carboplatin led to a significantly greater growth inhibition in A549 lung cancer cells than chemotherapy alone. Ovarian cancer also has been rendered sensitive when treated with Vorinostat combined with Carboplatin [30].

While applying Vorinostat combined with Cyclophosphamide at a concentration of $3 \mu \mathrm{M}$ was the less effective combination, as it yielded the highest number of viable cells $\left(150,000\right.$ viable cells out of $6 \times 10^{5} ; 75 \%$ mortality rate). Combination of novel agents with conventional induction and maintenance regimens is a promising strategy for the treatment of several malignancies like lung cancer [31]. It was reported earlier that Cyclophosphamide combined with Vorinostat was feasible and tolerable [32]. This was in accordance with our data, although this conclusion may warrant further study.

In addition, ongoing studies are investigating the combination of Vorinostat with Temozolomide [33]. On the other hand, different drug combinations have resulted in different cell viability profiles indicating that even the lower concentrations were capable to induce cell death [29]. This reduction in the cell number might be attributed to the activation of the internal apoptotic machinery as indicated elsewhere $[34,35]$. 


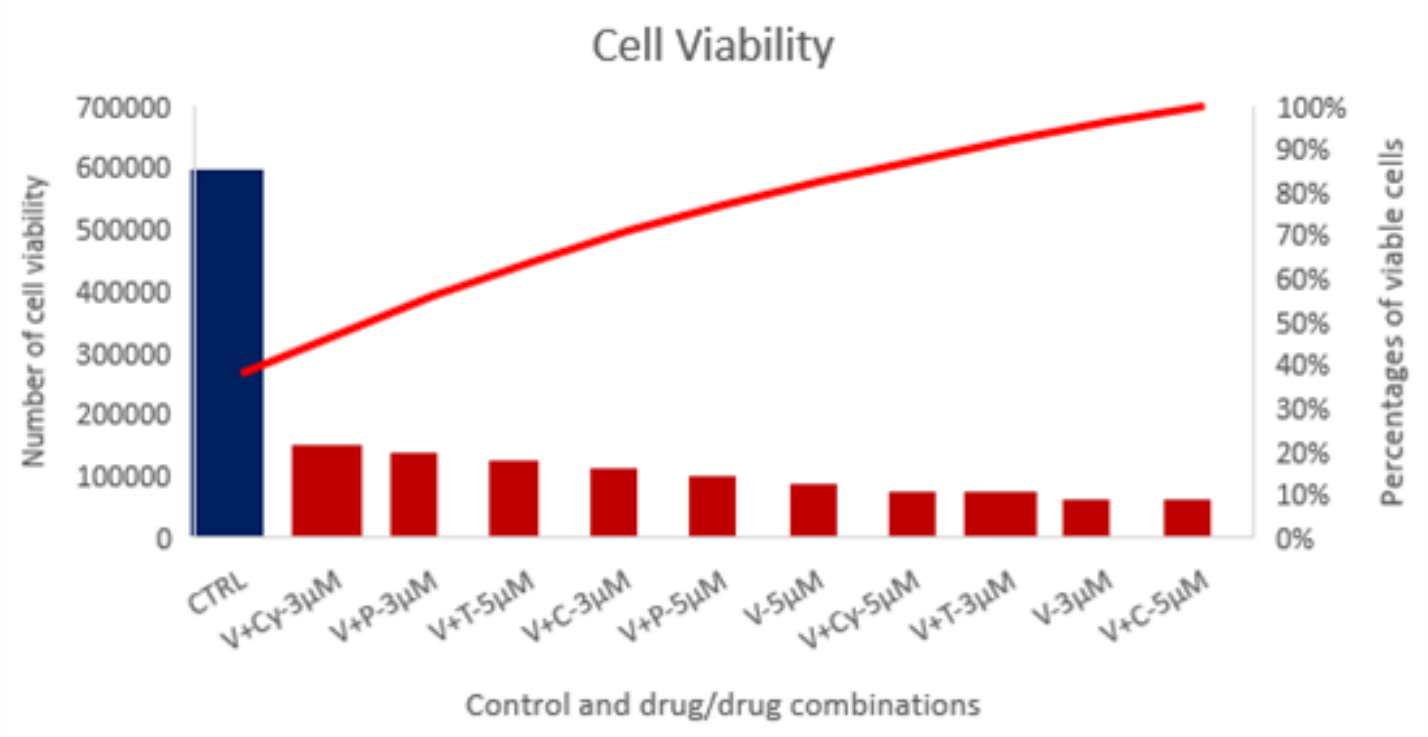

Figure 1: Cell viability test results. CTRL: Control, V: Vorinostat, C: Carboplatin Cy: Cyclophosphamide, P: Procaine, and T: Temozolomide.

\section{DNA fragmentation assay}

DNA fragmentation is a method used to identify the effect of treating cancer cell lines with chemotherapeutic drugs [36]. Here in the present study we assessed DNA fragmentation occurred in lung cancer cells A549 after being treated with different combinations/concentrations of chemotherapeutics. The data obtained showed a severe damage in cellular DNA in all treated cells regardless the drug/drug combination compared to control. The most effective drug combination in inducing DNA fragmentation was Vorinostat combined with Carboplatin at the concentration of $5 \mu \mathrm{M}$ and Vorinostat at concentration $5 \mu \mathrm{M}$. The rest of the combinations could degrade DNA with less severity as shown in figure (2). Several researches indicated that chemotherapeutic treatment of cancer cell might induce DNA fragmentation, which will lead to apoptosis [37-40].

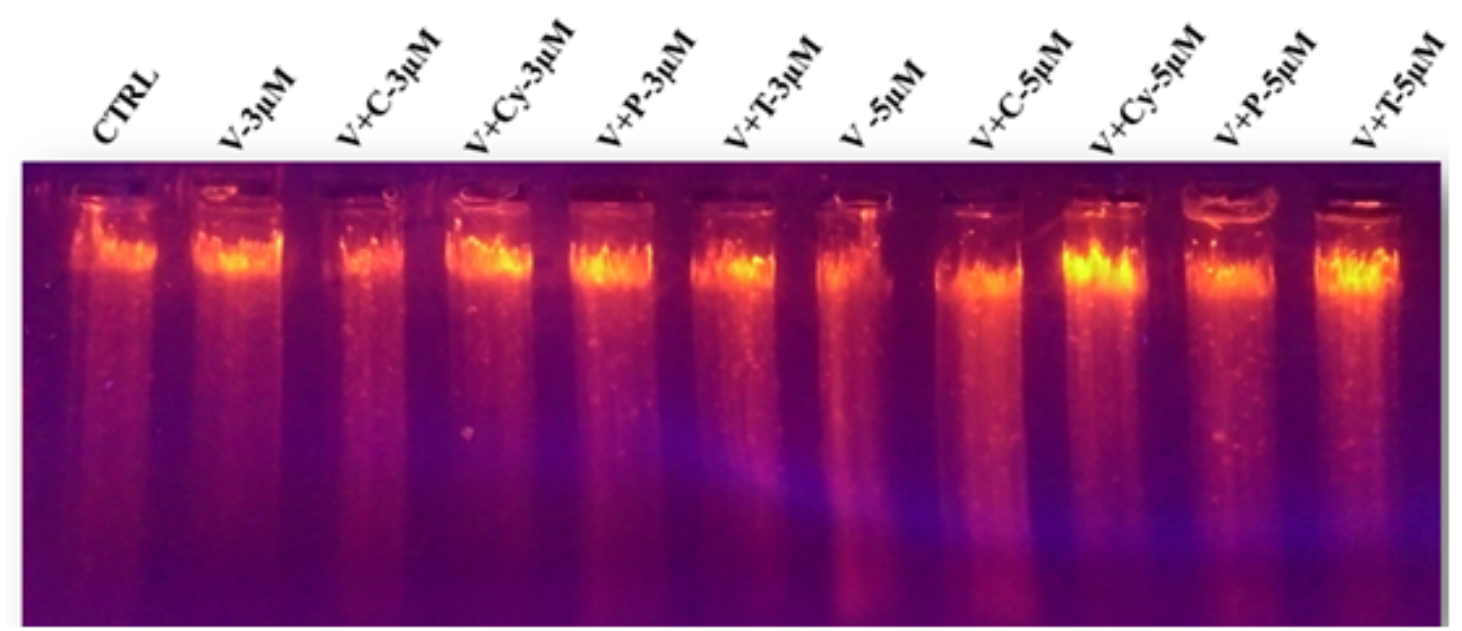

Figure 2: The results of DNA fragmentation assay after treating the lung cancer cells with different chemotherapeutic drugs. CTRL: Control, V: Vorinostat, C: Carboplatin Cy: Cyclophosphamide, P: Procaine, and T: Temozolomide.

\section{Quantification of DNA methylation}

Global methylation pattern was identified using the EZ DNA Methylation $^{\mathrm{TM}}$ Kit (Zymo Research, USA) in DNA extracted from both treated and untreated lung cancer cells A549. A standard curve was generated to calculate the corrected 5-MethylCytosine concentrations.

DNA methylation patterns are largely modified in cancer cells compared to control, and can therefore be used to distinguish cancer cells from normal tissues [41]. Results obtained (Figure $3 \& 4$ ) showed a significant variation in the patterns of global methylation between different treatments.
Some drugs/combinations (Vorinostat combined with Procaine at concentration $3 \mu \mathrm{M}$, Vorinostat combined with Temozolomide at the concentration of $5 \mu \mathrm{M}$, Vorinostat at the concentration of $3 \mu \mathrm{M}$, Vorinostat combined with Carboplatin at the concentration of $5 \mu \mathrm{M}$, and Vorinostat combined with Cyclophosphamide at the concentration of $3 \mu \mathrm{M})$ were able to globally hypomethylate the lung cancer cells A549. Genome-wide studies showed that reactivation of hypermethylated genes by combining more than one drug was significantly better than that induced by only one chemotherapeutic agent [42]. 


\section{International Journal of Science and Research (IJSR) \\ ISSN (Online): 2319-7064}

Index Copernicus Value (2015): 78. 96 | Impact Factor (2015): 6. 391

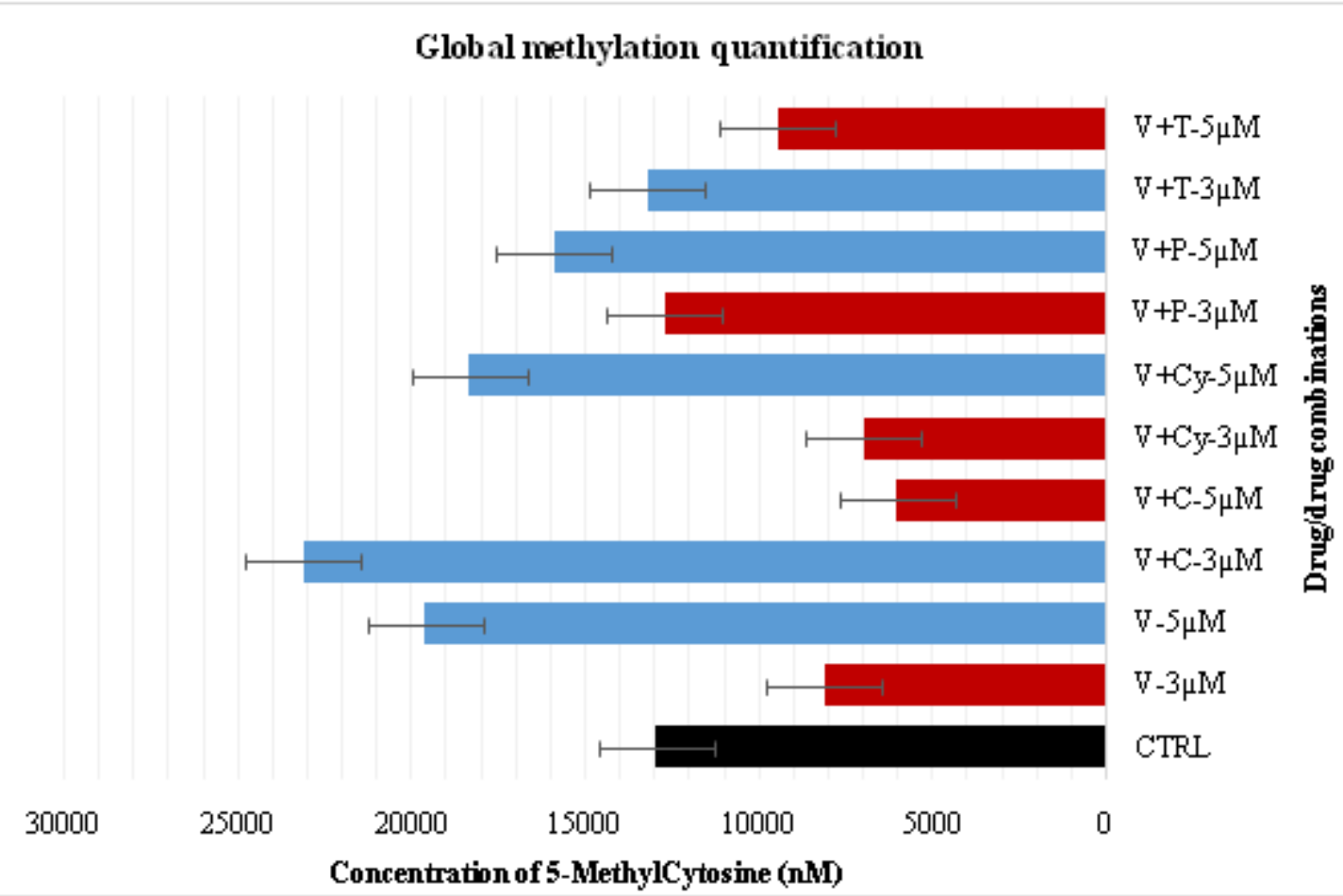

Figure 3: Global quantification of DNA methylation. CTRL: Control, V: Vorinostat, C: Carboplatin Cy: Cyclophosphamide, P: Procaine, and T: Temozolomide.

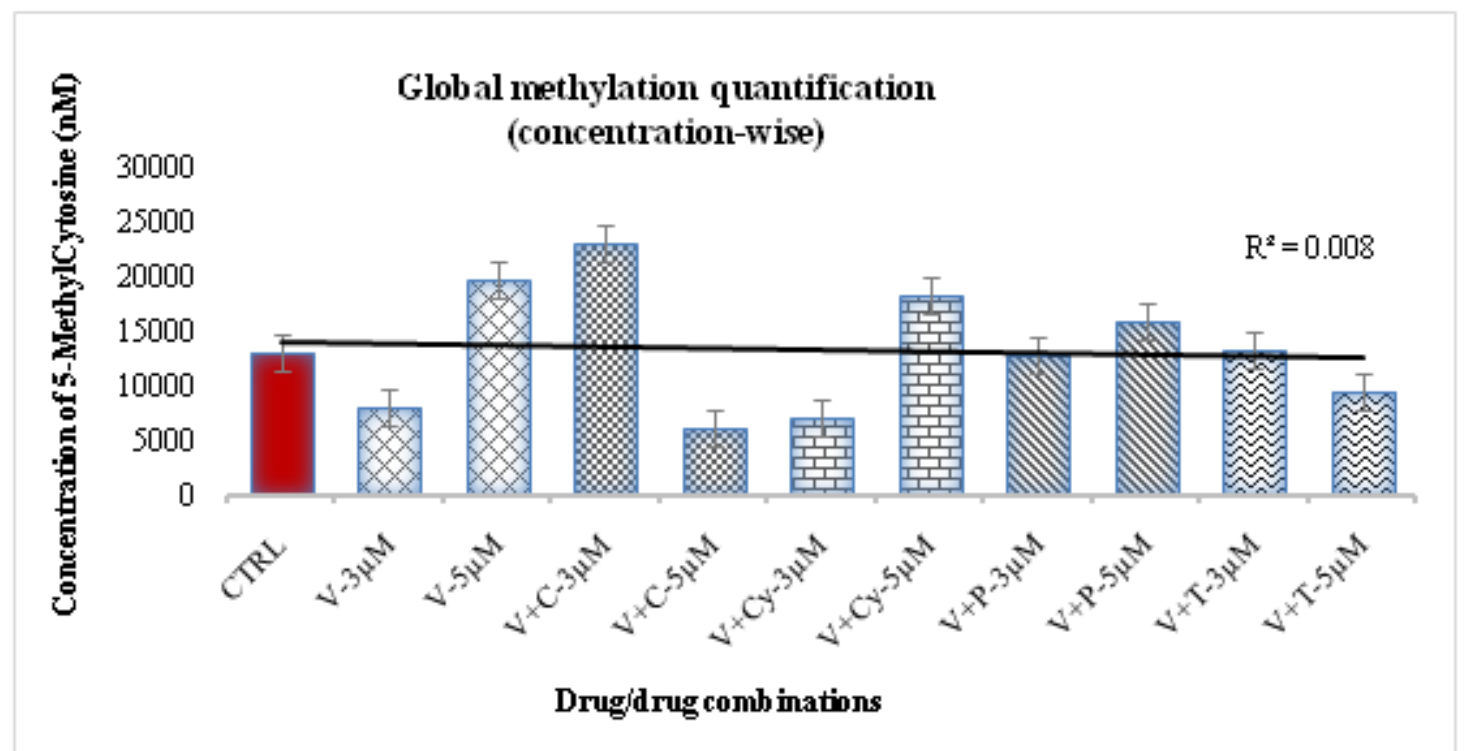

Figure 4: Global quantification of DNA methylation. Data were arranged in concentration-based manner. CTRL: Control, V: Vorinostat, C: Carboplatin Cy: Cyclophosphamide, P: Procaine, and T: Temozolomide.

It was indicated earlier that histone and DNA methylation patterns in several malignant cells could be partially modified by the clinically promising HDAC inhibitor, Vorinostat [43]. Temozolomide shows its anti-cancer activity by methylating the DNA, as the interaction between DNA and Temozolomide causes localized distortion of DNA away from the normal B-form, resulting in a wider major groove and greater steric accessibility of functional groups in the base of the groove [44]. The ability of Temozolomide to methylate histones confers to its potentially unique mechanism of action [45].

Meanwhile, other drugs/combinations (Vorinostat combined with Procaine at the concentration of $5 \mu \mathrm{M}$, Vorinostat combined with Cyclophosphamide at the concentration of $5 \mu \mathrm{M}$, Vorinostat combined with Carboplatin at the concentration of $3 \mu \mathrm{M}$, Vorinostat at the concentration of $5 \mu \mathrm{M}$ and Vorinostat combined with Temozolomide at the concentration of $3 \mu \mathrm{M}$ ) were able to globally hypermethylate the cells under study. Procaine also has growth-inhibitory effects, as it causes mitotic arrest. Thus, Procaine could be considered as a promising candidate for future epigeneticsbased cancer therapies [46].

Chemotherapeutic drugs have different mechanisms in inducing cell death [47]. HDAC inhibitor, like Vorinostat tends to hypomethylate lung cancer cells when applied solely in low concentration $[\mathbf{4 8 , 4 9 ]}$, while applying a

\section{Volume 6 Issue 7, July 2017}

www. ijsr. net 


\section{International Journal of Science and Research (IJSR) \\ ISSN (Online): 2319-7064}

Index Copernicus Value (2015): 78. 96 | Impact Factor (2015): 6. 391

combination contained DNMT inhibitor and HDAC inhibitor might hypermethylate the cells, and hence down regulates several tumor suppression-related genes $[\mathbf{1 1}, \mathbf{5 0}]$.

\section{Conclusion}

In the present study, the role of Vorinostat and other chemotherapeutic drugs (Carboplatin, Cyclophosphamide, Procaine, and Temozolomide) were evaluated as controller of the proliferation of lung cancer cells A549. Two final concentration of the drugs were applied $(3 \mu \mathrm{M}$ and $5 \mu \mathrm{M})$ to the cells, incubated for 96 hand cells viability were measured using the Trypan blue test. The global methylation pattern was assessed, and the results obtained indicated that different drug combinations were capable to hypo/hypermethylated the lung cancer cells A549. The present investigation needs more confirmatory studies to identify the actual mechanism (s) by which these drugs could control the malignant cells proliferation.

\section{Conflict of Interests}

The authors declare no conflict of interests.

\section{Author Contribution}

HS: put the idea and wrote the manuscript, MF: conducted the experiments, SEA: performed the statistical analysis and formatted the references, OAMS: participated in writing the manuscript and editing the references, and MME: critically revised the final manuscript.

\section{Acknowledgement}

This work was conducted in the labs of the College of Biotechnology, Misr University for Science \& Technology. The authors thank Mr. Basel Al-Azab for his kind help.

\section{References}

[1] Rakoff-Nahoum, S. (2006). Cancer Mechanisms: Why Cancer and Inflammation? Yale Journal of Biology and Medicine 79, pp. 123-130.

[2] Hanahan, D. and R. A. Weinberg (2011). Hallmarks of Cancer: The Next Generation. cell. 02. 013.

[3] Didkowska, J.; U. Wojciechowska; M. Mańczuk, and J. Lobaszewski (2016). Lung cancer epidemiology: contemporary and future challenges worldwide. Ann Transl Med.; 4 (8): 150.

[4] Alberg, A. J.; M. V. Brock, J. G. Ford , J. M. Samet, S. D. Spivack (2013). Epidemiology of lung cancer: Diagnosis and management of lung cancer, 3rd ed: American College of Chest Physicians evidence-based clinical practice guidelines. Chest; 143 (5 Suppl): e1S29S.

[5] Dubey, A. K.; U. Gupta; and S. Jain (2016). Epidemiology of lung cancer and approaches for its prediction: a systematic review and analysis. Chin J Cancer; 35: 71.

[6] Siegel, R. L.; K. D. Miller, and A. Jemal (2016). Cancer Statistics. CA Cancer J CLIN 20; 66. 7-30.
[7] Partridge, A. H.; H. J. Burstein; and E. P. Winer (2001). Side effects of chemotherapy and combined chemohormonal therapy in women with early-stage breast cancer. J Natl Cancer Inst Monogr.; (30): 135-42.

[8] Weeks, J. C.; P. J. Catalano; A. Cronin; M. D. Finkelman; J. W. Mack, N. L. Keating; and D. Schrag (2012). Patients' Expectations about Effects of Chemotherapy for Advanced Cancer. N Engl J Med; 367: 1616-1625.

[9] Kreidieh, F. Y.; H. A. Moukadem; and N. S. El Saghir (2016). Overview, prevention and management of chemotherapy extravasation. World J ClinOncol.; 7 (1): 87-97.

[10] Malhotra, V. and M. C. Perry (2013). Classical chemotherapy: mechanisms, toxicities and the therapeutic window. Cancer Biol. Ther, 263 (1): 12-19.

[11] Pan, C.; Y. Chang; M. Lee; B. Wen; J. Ko; S. Liang; and M. Liang (2016). Vorinostat enhances the cisplatin-mediated anticancer effects in small cell lung cancer cells. BMC Cancer, 16: 857.

[12] Bubna, A. K. (2015). Vorinostat an Overview. Indian J Dermatol.; 60 (4): 419.

[13] Waddington, C. H. (1942). Theepigenotype. Endeavour; 1: 18-20.

[14] Waddington, C. H. (1968). Towards a Theoretical Biology. Edinburgh, Scotland: Edinburgh University Press; the Basic Ideas of Biology; pp. 1-32.

[15] Casati, L.; A. Colciago; and F. Celotti (2010). Epigenetic Mechanisms in Health and Diseases. Brasília Med; 48 (2): 209-218.

[16] Dawson, M. A. and T. Kouzarides (2013). Cancer epigenetics: from mechanism to therapy. Cell, 150: 1227.

[17] Slatkin, M. (2009). Epigenetic Inheritance and the Missing Heritability Problem. Genetics; 182 (3): 845850.

[18] Messerschmidt, D. M.; B. B. Knowles; and D. Solter (2014). DNA methylation dynamics during epigenetic reprogramming in the germline and preimplantation embryos. Genes \& Dev. 28: 812-828.

[19] Robertson, K. D. (2005). DNA methylation and human disease. Nat Rev Genet; 6 (8): 597-610.

[20]Jin, B.; Y. Li; and K. D. Robertson (2011). DNA Methylation: Superior or Subordinate in the Epigenetic Hierarchy? Genes \& Cancer 2 (6) 607-617.

[21] West, A. C. and R. W. Johnstone (2014). New and emerging HDAC inhibitors for cancer treatment. J Clin Invest.; 124 (1): 30-39.

[22] Li, Y. and E. Seto (2016). HDACs and HDAC Inhibitors in Cancer Development and Therapy. Cold Spring Harb Perspect Med; 6: a026831.

[23] Ropero, S. and M. Esteller (2007). The role of histone deacetylases (HDACs) in human cancer. Molecular Oncology 1, 19-25.

[24] Ceccacci, E. and S. Minucci (2016). Inhibition of histone deacetylases in cancer therapy: lessons from leukaemia. Br J Cancer; 114 (6): 605-611.

[25] Strober, W. (2001). Trypan blue exclusion test of cell viability. Curr ProtocImmunol.; Appendix.

[26] Pallant, J. (2010). SPSS survival manual: a step by step guide to data analysis using SPSS. Maidenhead: Open University Press/McGraw-Hill. 


\section{International Journal of Science and Research (IJSR) \\ ISSN (Online): 2319-7064}

Index Copernicus Value (2015): 78. 96 | Impact Factor (2015): 6. 391

[27] Ricardo, R. and K. Phelan (2008). Counting and Determining the Viability of Cultured Cells. J. Vis. Exp, (16), e752.

[28] Ramalingam, S. S.; M. L. Maitland; P. Frankel; A. E. Argiris; M. Koczywas; B. Gitlitz; S. Thomas; I. Espinoza-Delgado; E. E. Vokes; D. R. Gandara; and C. P. Belani (2010). Carboplatin and Paclitaxel in Combination with Either Vorinostat or Placebo for First-Line Therapy of Advanced Non-Small-Cell Lung Cancer. Journal of clinical oncology. Volume 28 number 1.

[29] Owonikoko, T. K.; S. S. Ramalingam; B. Kanterewicz; T. Balius; C. P. Belani; and P. A. Hershberger (2010). Vorinostat increases Carboplatin and paclitaxel activity in non-small cell lung cancer cells. Int J Cancer.; 126 (3): 743-755.

[30] Matulonis, U.; S. Berlin; H. Lee; C. Whalen; E. Obermayer; R. Penson; J. Liu; S. Campos; C. Krasner; and N. Horowitz (2015). Phase I study of combination of Vorinostat, Carboplatin, and gemcitabine in women with recurrent, platinumsensitive epithelial ovarian, fallopian tube, or peritoneal cancer. Cancer Chemother Pharmacol.; 76 (2): 417-23.

[31] Shadman, M.; A. K Gopal; O. Press; D. G. Maloney; R. Mawad; T. Wadsworth; T. W. Dennie; K. Schultheiss; K. Kojouri; B. E. Kammerer; and J. M. Pagel (2016). Fludarabine, Cyclophosphamide, Rituximab (FCR) and Vorinostat Followed By Rituximab and Vorinostat Maintenance Therapy in Patients with Previously Untreated Chronic Lymphocytic Leukemia (CLL) or Small Lymphocytic Leukemia (SLL) - Final Results of a Phase I/II Study. Blood 128: 4396.

[32] Mawad, R.; A. K. Gopal; O. W. Press; D. G. Maloney; S. H. Petersdorf; T. Wadsworth; T. W. Dennie; Y. Inoue; K. J. Schultheiss; K. Kojouri; K. M. Smith; B. Kammerer; and J. M. Pagel (2013). A Phase I/II Study of Fludarabine, Cyclophosphamide, Rituximab and Vorinostat Followed By Rituximab and Vorinostat Maintenance Therapy In Patients With Previously Untreated B-Cell Chronic Lymphocytic Leukemia (CLL) Or Small Lymphocytic Leukemia (SLL). Blood 122: 4191.

[33] Kufahl, P. R.; P. Barbara; C. Hastengard; and M. F. Olive (2013). Potential use of antidepressant as therapies for drug use disorders. Att-ur-Rahman ed. CNS and neurological disorders. Vol. frontiers in clinical drug research. Bentham eBooks, 3-37.

[34] Sarkar, D. (2009). Commentary HDAC inhibitors and ionizing radiation Combinatorial strategy to combat lung cancer. Cancer Biology \& Therapy 8: 9, 832-834.

[35] DeVita, V. T. and E. Chu (2013). A definition of cancer chemotherapy. Cancer Res, 68 (21): 8643-53.

[36] Unger, F. T.; I. Witte, and K. A. David (2015). Prediction of individual response to anticancer therapy: historical and future perspectives Cell Mol Life Sci.; 72: 729-757.

[37] Pawlak, A.; A. Rapak; I. Zbyryt; and B. ObmińskaMrukowicz (2014). The Effect of Common Antineoplastic Agents on Induction of Apoptosis in Canine Lymphoma and Leukemia Cell Lines. In vivo 28: $843-850$.
[38] Gregoraszczuka, E. L.; A. Rak-Mardyłaa; J. Ryśb; J. Jakubowiczc; and K. Urbańskic (2015). Effect of Chemotherapeutic Drugs on Caspase-3 Activity, as a Key Biomarker for Apoptosis in Ovarian Tumor Cell Cultured as Monolayer. A Pilot Study. Iranian Journal of Pharmaceutical Research, 14 (4): 1153-1161.

[39] Sabit, H.; M. B. Samy; O. A. M. Said; and M. M. ElZawahri (2016). Procaine Induces Epigenetic Changes in HCT116 Colon Cancer Cells. Genet Res Int. 2016; 8348450 .

[40] Lompardía, S. L.; M. Díaz; D. L. Papademetrio; M. Mascaró, M. Pibuel, E. Álvarez, and S. E. Hajos (2016). Hyaluronan oligomers sensitize chronic myeloid leukemia cell lines to the effect of Imatinib. Glycobiology, vol. 26, no. 4, 343-352.

[41] Delpu, Y.; P. Cordelier; W. C. Cho; and J. Torrisani (2013). DNA Methylation and Cancer Diagnosis. Int J Mol Sci.; 14 (7): 15029-15058.

[42] Qin, T.; J. Si; N. J. Raynal; X. Wang; V. Gharibyan; S. Ahmed; X. Hu; C. Jin; Y. Lu; J. Shu; M. R. H. Estecio; J. Jelinek; and J. J. Issa (2015). Epigenetic synergy between decitabine and platinum derivatives. Clin Epigenetics.; 7 (1): 97.

[43] Foltankova, V.; S. Legartova; S. Kozubek; and E. Bartova (2012). Tumor-specific histone signature and DNA methylation in multiple myeloma and leukemia cells. Neoplasma.; 59 (4): 450-62.

[44] Topkaya, S. N.; G. Serindere; and M. Ozder (2016). Determination of DNA Hypermethylation Using Anticancer Drug-Temozolomide. Electroanalysis. Volume 28, Issue 5, Pages 1052-1059.

[45] Pickard, A. J.; A. J. Diaz; H. Mura; L. Nyuwen; D. Coello; S. Sheva; N. Maria; J. M. Gallo; and T. Wang (2016). Histone Methylation by Temozolomide; A Classic DNA Methylating Anticancer Drug. Anticancer Res.; 36 (7): 3289-3299.

[46] Villar-Garea, A.; M. F. Fraga; J. Espada; and M. Esteller (2003). Procaine Is a DNA-demethylating Agent with Growth-inhibitory Effects in Human Cancer Cells. Cancer Research 63, 4984-4989.

[47] Dupéré-Richer, D.; M. Kinal; V. Ménasché; T. H. Nielsen; S. Del-Rincon; F. Pettersson; and W. H. Miller (2013). Vorinostat-induced autophagy switches from a death promoting to a cytoprotective signal to drive acquired resistance. Cell Death and Dis. $7 ; 4$ e486.

[48] Mottamal, M.; S. Zheng; T. L. Huang; and G. Wang (2015). Histone Deacetylase Inhibitors in Clinical Studies as Templates for New Anticancer Agents. Molecules, 20, 3898-3941.

[49] Jakopovic, M.; A. Thomas; S. Balasubramaniam; D. Schrump; G. Giaccone; and S. E. Bates (2013). Targeting the epigenome in lung cancer: expanding approaches to epigenetic therapy. Front Oncol. 9; 3: 261.

[50] Lee, J. and S. Huang (2014). Cancer Epigenetics: Mechanisms and Crosstalk of a HDAC Inhibitor, Vorinostat. Chemotherapy (Los Angel); 2 (111) 